\title{
Biliary Excretion of Iron from Hepatocyte Lysosomes in the Rat A Major Excretory Pathway in Experimental Iron Overload
}

\author{
Gene D. LeSage, Louis J. Kost, Steven S. Barham, and Nicholas F. LaRusso \\ Gastroenterology Research Unit, Departments of Internal Medicine and Cell Biology, \\ Mayo Clinic and Foundation, Rochester, Minnesota 55905.
}

\section{Abstract}

In these experiments, we assessed the role of hepatocyte lysosomes in biliary excretion of iron. We loaded rats with iron by feeding $2 \%$ carbonyl iron and collected bile for $24 \mathrm{~h}$ via bile fistulae from iron-loaded and control rats. In additional rats, bile was collected before and after the administration of colchicine. Rats were then killed and their livers were homogenized and fractionated for biochemical analyses or processed for electron microscopy and $x$-ray microanalysis. Inclusion of $2 \%$ carbonyl iron in the diet caused a 45 -fold increase $(P<0.001)$ in hepatic iron concentration compared with controls $(1,826 \pm 159$ vs. $38 \pm 6.7$ $\mu \mathrm{g} / \mathrm{g}$ liver, mean $\pm \mathrm{SE}$ ). Electron microscopy with quantitative morphometry and $x$-ray microanalysis showed that the excess iron was sequestered in an increased number of lysosomes concentrated in the pericanalicular region of the hepatocyte. Iron loading was also associated with a twofold increase in biliary iron excretion $(4.06 \pm 0.3$ vs. $1.75 \pm 0.1 \mu \mathrm{g} / \mathrm{g}$ liver $/ 24 \mathrm{~h} ; P$ $<0.001)$. In contrast, the biliary outputs of three lysosomal enzymes were significantly lower $(P<0.0005)$ in iron-loaded rats compared with controls (mean $\pm \mathrm{SE}$ ) expressed as $\mathrm{mU} / 24 \mathrm{~h} / \mathrm{g}$ liver: $N$-acetyl- $\beta$-glucosaminidase, $26.7 \pm 4.6$ vs. $66.2 \pm 13.4 ; \beta$ glucuronidase, $10.1 \pm 1.3$ vs. 53.2 $\pm 17.9 ; \beta$-galactosidase, $8.9 \pm 1.0$ vs. 15.4 \pm 2.3 . In iron-loaded rats but not in controls, biliary iron excretion was coupled to the release into bile of each of the three lysosomal hydrolases as assessed by linear regression analysis $(P<0.001)$. In contrast, no relationships were found between biliary iron excretion and the biliary outputs of a plasma membrane marker enzyme (alkaline phosphodiesterase I) or total protein. After administration of colchicine, there was a parallel increase in biliary excretion of iron and lysosomal enzymes in iron-loaded rats, but not controls. We interpret these data to indicate that, in the rat, biliary iron excretion from hepatocyte lysosomes is an important excretory route for excess hepatic iron.

Portions of this work were presented at the meeting of the American Gastroenterological Association, 1983; and at the meeting of the American Association for the Study of Liver Diseases, 1984; and were published in abstract form, 1983, Gastroenterology. 84:1381; and 1984. Hepatology. 4:1077.

Dr. LeSage was a Research Fellow in the Gastroenterology Unit. His present address is Scott and White Clinic, Temple, TX 76508. Address correspondence to Dr. LaRusso, Professor of Medicine and Associate Professor of Cell Biology, Gastroenterology Unit, Mayo Medical School, Clinic, and Foundation, Rochester, MN 55905. 1985.

Received for publication 3 May 1985 and in revised form 6 August

J. Clin. Invest.

(c) The American Society for Clinical Investigation, Inc.

0021-9738/86/01/0090/08 $\$ 1.00$

Volume 77, January 1986, 90-97

\section{Introduction}

Lysosomes are intracellular, membrane-bound organelles that contain over $\mathbf{4 0}$ hydrolytic enzymes with an acid pH optimum. The major functions of lysosomes include intracellular digestion, transcellular transport, extracellular release or secretion of their contents, and the sequestration and storage of endogenous or exogenous cell components (1). Several years ago, we proposed that exocytosis of lysosomal contents into biliary canaliculi was an important excretory pathway in the liver (2), a hypothesis originally suggested by de Duve and Wattiaux (3). Subsequent studies have produced results consistent with this hypothesis and have included: $(a)$ the demonstration of coordinate release of several lysosomal hydrolases into bile under basal (2) and cholestatic (4) conditions; $(b)$ the observation that an exogenous lysosomotropic agent is excreted into bile in parallel with endogenous lysosomal constituents under basal (5) or stimulated conditions; and $(c)$ the finding that the biliary excretion of lysosomal enzymes can be altered by pharmacologic agents (6) and is a microtubule-dependent process (7). Thus, our studies have been consistent with the possibility that this lysosome-tobile hepatic excretory pathway is involved in the metabolism and subsequent biliary excretion of a variety of circulating molecules (e.g., proteins [8], lipoproteins [9], and trace metals) destined for sequestration in hepatocyte lysosomes.

It is well known that iron may accumulate in the liver in genetic hemochromatosis (10), after multiple blood transfusions (11) or excessive oral intake of iron (12). In all these disorders, the excess hepatic iron conspicuously accumulates in hepatocyte lysosomes, as shown by both biochemical (13) and morphologic (14) studies. The mechanism whereby iron is sequestered in hepatocyte lysosomes in conditions of iron overload is not known. Nevertheless, the consistent pericanalicular location of iron-laden lysosomes within hepatocytes and the demonstration that there are significant amounts of iron in bile (15) has led investigators to suggest that iron may be released into bile directly from hepatocyte lysosomes by exocytosis after fusion of lysosomes with the canalicular membrane. There is, however, no direct morphologic or biochemical evidence for the existence of this excretory pathway.

Therefore, we examined in detail the role of hepatocyte lysosomes in the biliary excretion of iron. To this end, we applied an animal model of iron overload to examine the subcellular distribution of iron in the livers of normal and iron-loaded rats, assessed the relationship between biliary iron excretion and the release into bile of lysosomal and plasma membrane enzymes, and examined the effect of a microtubule binding agent, colchicine, on biliary iron excretion. Our results show that, in the condition of hepatic iron overload, excess iron is sequestered in hepatocyte lysosomes, biliary iron excretion is increased, the accelerated release of excess iron into bile is closely coupled to biliary excretion of lysosomal but not plasma membrane en- 
zymes, and colchicine augments biliary excretion of both iron and lysosomal enzymes in a coordinate fashion.

\section{Methods}

General experimental procedure. Male Sprague Dawley rats were fed either standard laboratory chow (Ralston Purina Co., St. Louis, MO) or laboratory chow containing $2 \%$ carbonyl iron (Ralston Purina Co.) according to the method of Bacon et al. (16) for up to $6 \mathrm{mo}$. The rats were permitted free access to food and water until $7 \mathrm{a} . \mathrm{m}$. on the morning of the experiment.

In one group of experiments, control rats $(n=10)$ and iron-fed rats $(n=9)$ were weighed and complete bile fistulae were created under pentobarbital anesthesia ( $40 \mathrm{mg} / \mathrm{kg}$ body weight) as previously described (2). After surgery, rats were placed in restraining cages and bile was collected into preweighed, acid-washed polypropylene containers in 2hourly aliquots for $24 \mathrm{~h}$.

In another set of experiments, additional iron-loaded $(n=11)$ and control $(n=11)$ animals had bile fistulae established and anesthesia maintained with repeated doses of intraperitoneal sodium pentobarbital. Tracheostomies were performed to facilitate respiration, $5 \%$ dextrose was infused into the femoral vein at $1.5 \mathrm{ml} / \mathrm{h}$, and animals were placed in a constant temperature-humidity apparatus where bile was collected for a total of $8 \mathrm{~h}$. After $4 \mathrm{~h}$ of bile collection as a baseline, we administered either colchicine ( $5 \mu \mathrm{mol} / \mathrm{kg}$ body weight) or normal saline and collected bile for an additional $4 \mathrm{~h}$.

Rats from each set of experiments were killed by exsanguination after bile collection for either 24 or $8 \mathrm{~h}$ and their livers were removed and quickly immersed in an ice-cold solution containing $250 \mathrm{mM}$ sucrose, $3 \mathrm{mM}$ imidizole, and $0.1 \%$ ethanol at $\mathrm{pH}$ 7.4. Six $\mathrm{g}$ of liver were homogenized and centrifuged to separate nuclei, unbroken cells, and tissue debris (pellet or $\mathrm{N}$-fraction) from other organelles and cell sap (supernate or E-fraction), as described $(5,17)$. In some experiments, the latent hydrolase activity in E-fractions of rat liver, expressed as a percent of total activity, was determined for $N$-acetyl- $\beta$-glucosaminidase by subtracting free activity (activity in the absence of $0.1 \%$ Triton X-100 in the assay mix) from total activity (activity in the presence of $0.1 \%$ Triton X-100 in the assay mix), dividing this number by total activity, and multiplying by 100 . This value normally is $80-85 \%$ of the total hepatic lysosomal enzyme activity and is an indirect measurement of the integrity of lysosomal membranes (3).

In a third set of experiments, the subcellular distribution of iron was determined in control and iron-loaded rats by differential centrifugation of rat liver using an ultracentrifuge (L2-65B; Beckman Instruments, Inc., Fullerton, CA) as previously described $(5,17)$. In these studies, the Efraction prepared by low-speed centrifugation was further separated into four additional fractions enriched in mitochondria (heavy mitochondrial or M-fraction), lysosomes (light mitochondrial or L-fraction), endoplasmic reticulum (P-fraction), and cytosol (final supernatant or S-fraction).

Analytical procedures. Three lysosomal glycosidases- $\beta$-glucuronidase (EC 3.2.1.31), $\beta$-galactosidase (EC 3.2.1.23), and $N$-acetyl- $\beta$-glucosaminidase (EC 2.3.1.30)—were assayed fluorometrically using 4-methylumbelliferyl substrates (Koch-Light Laboratories, Ltd., Colnbrook, Buckinghamshire, UK) as described by Peters et al. (18). Optimal assay conditions for liver and bile had been previously established (2). The following subcellular marker enzymes were employed for differential centrifugation of rat liver: alkaline phosphodiesterase I (plasma membrane) was assayed at pH 10.8 with p-nitrophenylthymidine-5-phosphate as substrate (19); malate dehydrogenase (mitochondria), by the method of Dupourque (20); esterase (endoplasmic reticulum), by the method of Leighton et al. (21); and lactate dehydrogenase (cytosol), by the method of Reeves and Femognori (22). Suitable enzyme and substrate blanks were carried out for all assays. For all enzymes, $1 \mathrm{U}$ of activity corresponded to the hydrolysis of $1 \mu \mathrm{mol}$ of substrate per minute.

Protein determinations were done by an automated Lowry procedure using bovine serum albumin as a standard (23).
Iron determinations were performed using atomic absorption spectrophotometry (model 5000; Elmer-Perkins, Norwalk, CT) (24). Bile was acidified with $1 \mathrm{~N}$ nitric acid $(1: 1, \mathrm{vol} / \mathrm{vol})$ to solubilize iron hydroxides before iron measurements.

Morphologic studies. Livers were obtained for morphology from a separate group of iron-loaded and control rats. In these studies, livers were fixed by perfusion in situ with Trump's fixative (25), containing $4 \%$ formaldehyde and $1 \%$ glutaraldehyde in a $0.2 \mathrm{M}$ sodium phosphate buffer, pH 7.2, for $10 \mathrm{~min}$. Then 2-mm cubes of liver were cut and placed in the same fixative for $2 \mathrm{~h}$ at $4^{\circ} \mathrm{C}$ and then rinsed overnight in phosphate buffer. For light microscopy, liver was embedded in paraffin and stained with Perls stain for iron (26). For electron microscopy, liver was postfixed in $1 \%$ osmium tetroxide, dehydrated in a graded series of ethanol, and embedded in Spurr's low-viscosity epoxy resin (27). Thin sections were cut with a diamond knife on an ultramicrotome (LKB Instruments, Inc., Gaithersburg, MD), stained with $3 \%$ aqueous uranyl acetate and $0.3 \%$ aqueous lead citrate, and examined with a transmission electron microscope (400; Philips Electronic Instruments, Inc., Mahwah, NJ).

Quantitative morphometry was performed to assess the distribution of lysosomes in the pericanalicular areas as previously described (6). A $2-\mu \mathrm{m}$ radius was arbitrarily defined as the pericanalicular area, and the number of lysosomes within that area counted at a print magnification of 22,500. 12 randomly selected liver plates were counted for each rat, and the specimens were coded so the electron microscopist was unaware of the treatment protocol. Lysosomes were defined morphologically as single, round, or ovoid, electron-dense bodies, limited by a unit membrane.

$X$-ray microanalysis. X-ray microanalysis in combination with electron microscopy using an $\mathrm{x}$-ray energy spectroscopy system (7000; Kevex Corp., Foster City, CA) interfaced with an electron microscope (EM 400; Philips Electronic Instruments, Inc.) was performed on rat liver (28) to determine semiquantitatively the subcellular distribution of iron. Briefly, an electron beam ( $500 \mathrm{~nm}$ spot size) is focused on the subcellular area of interest. A characteristic $x$-ray spectrum is emitted for iron; the emission intensity depends on the amount of iron present in the probed area. Lysosomal and nonlysosomal (cytosol) areas were probed, and the relative amounts of iron in these subcellular locations were quantified.

Statistical methods. The two groups of rats in the 24-h studies were compared with regard to body weight, liver weight, and total 24-h bile flow using a two-sample independent $t$ test. Hepatic concentrations of lysosomal enzymes and iron, and the 24-h total outputs of enzymes and iron were compared using multivariate analysis of covariance adjusting for the total 24-h bile flow as the covariate. The multivariate analyses simultaneously considered: $(a)$ hepatic concentration of the three lysosomal enzymes in one analysis; (b) the total 24-h output of the three lysosomal enzymes (after converting to log scale to stabilize variances in the two groups) in a second analysis; and (c) the hepatic concentration and 24-h total output (log scale) of iron in a third analysis. In addition, the 24-h outputs of the three lysosomal enzymes as a percentage of total liver content were each analyzed via a two-sample rank sum test (Wilcoxon test with continuity correction). Relationships between biliary outputs of iron and lysosomal enzymes were analyzed by regression analysis after $\log$ transformation of the data.

\section{Results}

\section{Body weight, liver weight, bile flow, and serum levels of} bilirubin and aspartate aminotransferase

Inclusion of $2 \%$ carbonyl iron in the diet for 3 mo resulted in a significantly lower $(P<0.05)$ body weight (mean \pm SE) in ironloaded rats $(n=9,383 \mathrm{~g} \pm 18)$ compared with controls $(n=10$, $429 \mathrm{~g} \pm 21$ ). There were no significant differences in liver weight between iron-loaded rats and control rats $(11.5 \pm 0.6$ vs. $10.8 \pm 0.5$ g) or in bile flow $(18.0 \pm 1.3$ vs. $20.1 \pm 0.6 \mathrm{ml} / 24 \mathrm{~h})$. When we compared total serum bilirubin and aspartate aminotransferase 
Table I. Hepatic Iron Concentration and Biliary

Iron Excretion in Control and Iron-loaded Rats*

\begin{tabular}{lccc}
\hline & Controls & Iron-loaded & $P$ value \\
\hline & $n=10$ & $n=9$ & \\
$\begin{array}{c}\text { Hepatic iron concentration } \\
\text { ( } \mu \mathrm{g} / \mathrm{g} \text { wet weight liver })\end{array}$ & $\begin{array}{c}( \pm 6.1 \\
\text { Biliary iron excretion }\end{array}$ & $\begin{array}{c}1,826 \\
( \pm 159)\end{array}$ & $<0.001$ \\
$(\mu \mathrm{g} / \mathrm{g}$ liver/24 $\mathrm{hrs})$ & 1.75 & 4.06 & $<0.001$ \\
\hline
\end{tabular}

* Results are given as mean \pm SEM.

levels from three control rats (hepatic iron, $52.4 \pm 10.8 \mu \mathrm{g} / \mathrm{gm}$ liver) to three iron-loaded rats (hepatic iron, $2,241 \pm 372 \mu \mathrm{g} / \mathrm{g}$ liver), we found no significant difference in total serum bilirubin levels $(0.17 \pm 0.09$ vs. $0.17 \pm 0.06 \mathrm{mg} / \mathrm{dl})$; aspartate aminotrans-
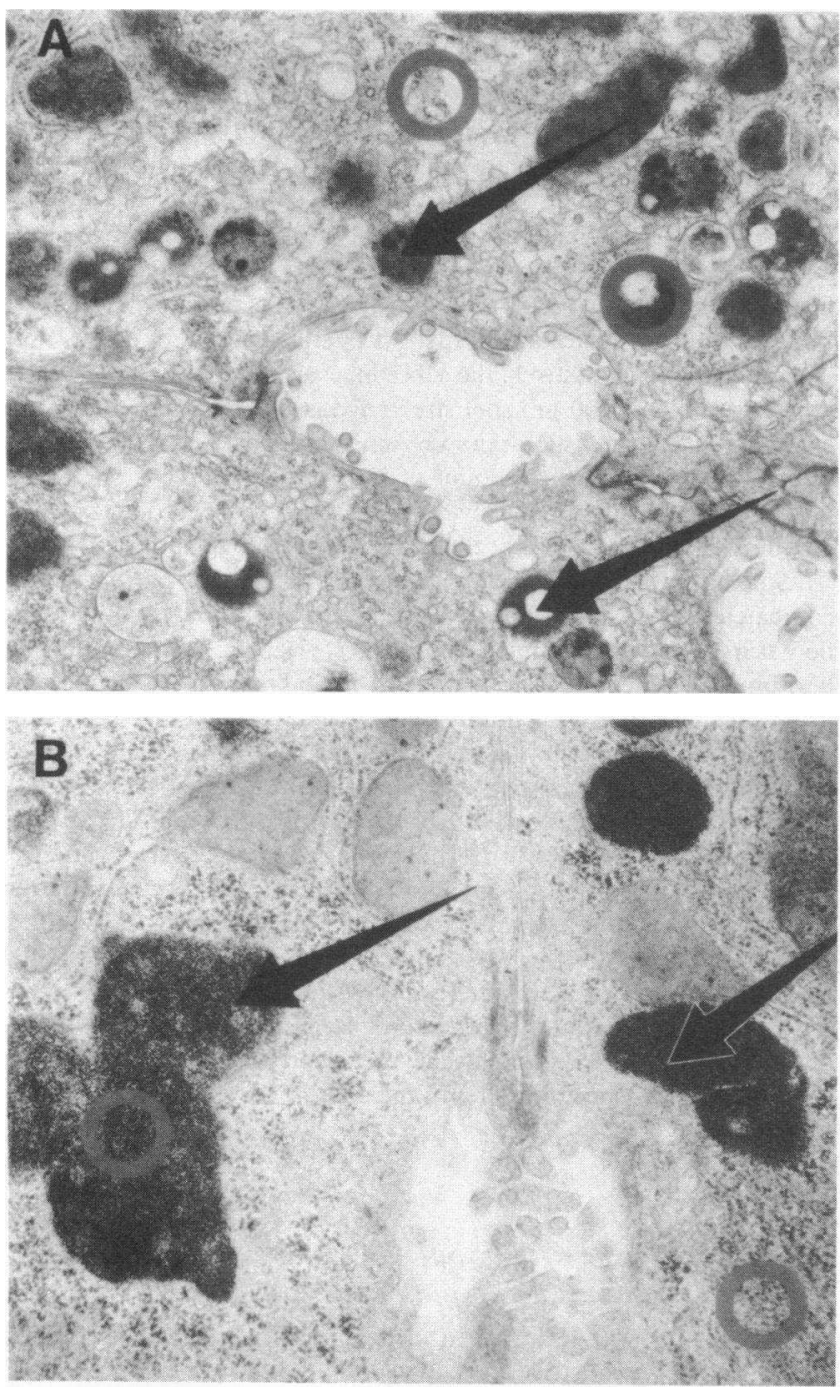

Figure 1. Transmission electron micrograph of a liver sample from a normal $(A)$ and an iron-loaded $(B)$ rat. Arrows indicate pericanalicular, lysosome-like structures in normal rat liver and electron dense, membrane-bound, pericanalicular organelles in iron-loaded rat liver. The circled areas were examined by $x$-ray microanalysis. $\times 62,500$. ferase levels were slightly but significantly $(P<0.05)$ higher in iron-loaded rats $(288 \pm 2.54 \mu /$ liter $)$ compared with controls

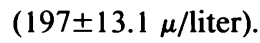

\section{Hepatic iron concentration and biliary iron output}

Hepatic concentrations of iron and 24-h outputs of iron into bile for rats fed a standard diet (controls) and for rats fed a standard diet containing $2 \%$ carbonyl iron for 3 mo (iron-loaded) are shown in Table $I$. The addition of iron to the diet was associated with a 45-fold increase in hepatic iron concentration and a twofold increase in biliary iron output compared with controls. The relationship between hepatic iron concentration and biliary output in either control $(r=-0.21 ; P>0.05)$ or iron-loaded $(r=0.36 ; P>0.05)$ rats was not statistically significant as assessed by regression analysis.

\section{Cellular and subcellular distribution of iron}

Light microscopy. Light microscopic examination of iron-loaded rats with Perl's staining showed heavy iron deposition, almost exclusively in periportal hepatocytes; only small amounts of stainable iron were seen in Kupffer cells (data not shown). No evidence of hepatocyte necrosis, cholestasis, inflammation, ductular proliferation, or fibrosis was evident in livers from ironloaded rats.

Transmission electron microscopy. An electron photomicrograph of the liver from a control rat is shown in Fig. $1 A$. Normal lysosome-like structures (arrows) are shown in the pericanalicular region. In contrast, an electron photomicrograph of the liver from an iron-loaded rat (Fig. $1 \mathrm{~B}$ ) shows electron dense granules within membrane-bound, pericanalicular organelles. These lysosomal-like structures, on higher magnification, contain hexagonal particles characteristic of ferritin (data not shown).

Quantitative morphometric analysis of the number of lysosomes in the pericanalicular area showed a progressive increase in the number of pericanalicular lysosomes as the duration of iron-loading was prolonged (Table II). Indeed, a reasonable correlation $(r=0.65 ; P=0.06)$ existed between the total hepatic iron content and the number of pericanalicular lysosomes.

$X$-ray microanalysis. The x-ray microanalysis energy emission spectra from an electron probe aimed at lysosomal or nonlysosomal areas in an iron-loaded rat is shown in Fig. 2; the peaks at 6.4 and $7.1 \mathrm{KeV}$ are the characteristic emission spectra for iron. Note that large amounts of iron were detected in lysosomal areas compared with nonlysosomal areas. The relative concentration of iron in each probed area was determined by the area under the peaks at 6.4 and $7.1 \mathrm{KeV}$. Livers from rats that were serially iron-loaded from 1 to 27 wk were examined. We found a progressive rise in the relative amounts of iron in lysosomal areas with increasing duration of iron-loading (Table II). In contrast, relative amounts of iron in nonlysosomal areas remained unchanged with iron-loading (Table II). In rats loaded for $3 \mathrm{mo}$, the ratio of iron in lysosomal areas compared with nonlysosomal areas was 19 to 1 (mean of eight probed areas from three rats). The high ratio of lysosomal to nonlysosomal iron concentration indicates that the excess iron is selectively compartmentalized to lysosomes.

Differential centrifugation. The subcellular distribution of iron was determined by differential centrifugation in a normal rat liver and livers from rats iron-overloaded for 1.5, 3, 5, and 61 wk (Fig. 3) by dietary carbonyl iron as described in Methods. In all animals studied, the majority of the iron was recovered in the S-fraction or cytosolic fraction. Increased liver iron was 
Table II. Effect of Sequential Iron-loading on the Subcellular Distribution of Iron and on the Number of Pericanalicular Lysosomes*

\begin{tabular}{|c|c|c|c|}
\hline & \multicolumn{2}{|c|}{ Relative iron concentration } & \multirow{2}{*}{$\begin{array}{l}\text { Number of } \\
\text { pericanalicula } \\
\text { lysosomes }\end{array}$} \\
\hline & $\begin{array}{l}\text { In lysosomal } \\
\text { areas }\end{array}$ & $\begin{array}{l}\text { In nonlysosomal } \\
\text { areas }\end{array}$ & \\
\hline Control & $\begin{array}{r}0.04 \\
( \pm 0.02)\end{array}$ & $\begin{array}{r}0.02 \\
( \pm 0.01)\end{array}$ & $\begin{array}{r}2.75 \\
( \pm 0.4)\end{array}$ \\
\hline $\begin{array}{l}\text { Iron-loaded } \\
\text { (1.5 wk) }\end{array}$ & $\begin{array}{r}0.12 \\
( \pm 0.02)\end{array}$ & $\begin{array}{r}0.02 \\
( \pm 0.01)\end{array}$ & $\begin{array}{r}3.00 \\
( \pm 0.6)\end{array}$ \\
\hline $\begin{array}{l}\text { Iron-loaded } \\
\text { (3 wk) }\end{array}$ & $\begin{array}{r}0.19 \\
( \pm 0.05)\end{array}$ & $\begin{array}{r}0.02 \\
( \pm 0.02)\end{array}$ & $\begin{array}{r}5.50 \\
( \pm 1.3)\end{array}$ \\
\hline $\begin{array}{l}\text { Iron-loaded } \\
\quad(5 \mathrm{wk})\end{array}$ & $\begin{array}{r}0.32 \\
( \pm 0.03)\end{array}$ & $\begin{array}{r}0.02 \\
( \pm 0.02)\end{array}$ & $\begin{array}{r}6.25 \\
( \pm 0.08)\end{array}$ \\
\hline $\begin{array}{l}\text { Iron-loaded } \\
\text { (27 wk) }\end{array}$ & $\begin{array}{r}0.36 \\
( \pm 0.08)\end{array}$ & $\begin{array}{r}0.02 \\
( \pm 0.01)\end{array}$ & $\begin{array}{l}8.0 \\
( \pm 1)\end{array}$ \\
\hline
\end{tabular}

* Results are presented as median \pm SEM for the 12 plates counted from two rats in each group.

Iron was quantitated by $\mathrm{x}$-ray microanalysis and expressed as the emission intensity for iron corrected for the emission of the titanium grid background.

Number of lysosomes in a $2-\mu \mathrm{m}$ radius from biliary canaliculus.

associated with a decrease in relative specific activity of $\beta$-galactosidase in the L-fraction. This finding was explained by the observation that the latency of lysosomal enzymes (see below) progressively decreased from $85 \%$ in control rats to $14 \%$ in rats fed carbonyl iron for $1 \mathrm{yr}$ in these same experiments.

Latency of lysosomal enzymes in rat liver. There was a marked and significant decrease in the latent activity of $\mathrm{N}$-acetyl$\beta$-glucosaminidase in the livers of iron-loaded rats compared with controls $(35.8 \pm 5 \%$ vs. $81.5 \pm 1 \%, P<0.001)$. Furthermore, a significant inverse relationship $(r=-0.90, P<0.001)$ between

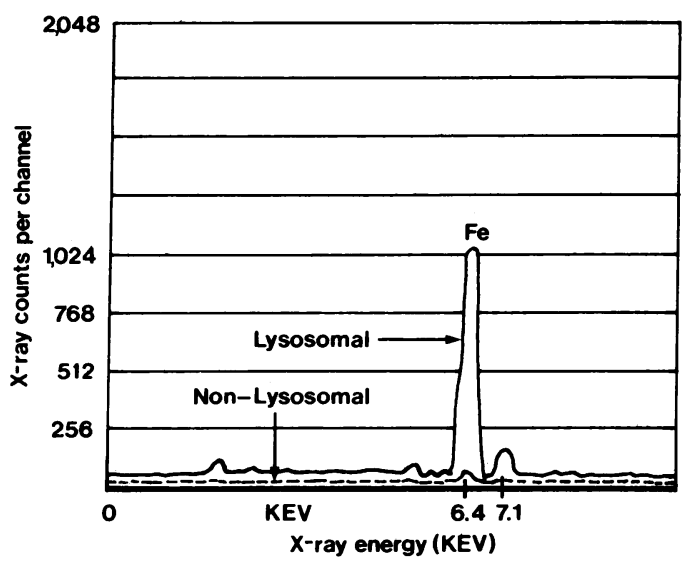

Figure 2. X-ray microanalysis energy emission spectra from a liver sample of an iron-loaded rat. Lysosomal and nonlysosomal areas were probed and their emission spectra are indicated by the solid and broken lines, respectively. Peaks at 6.4 and $7.1 \mathrm{keV}$ are the characteristic emission spectra for iron.

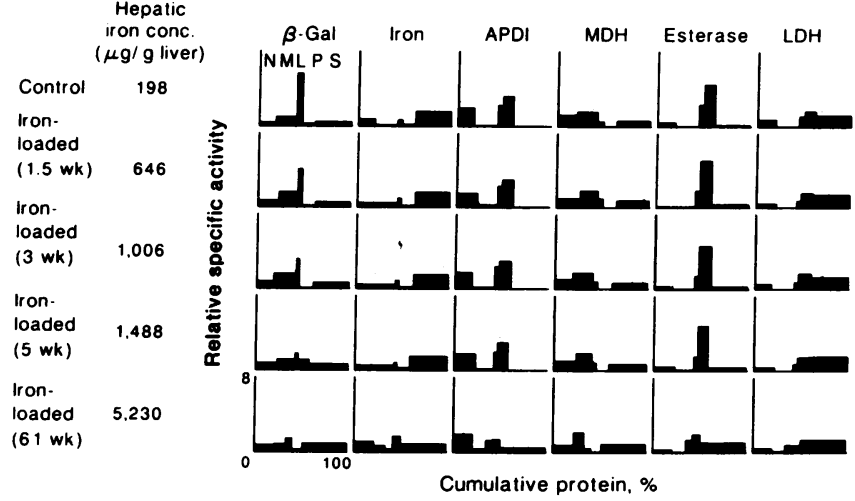

Figure 3. Distribution patterns of constituents after fractionation of rat liver by differential centrifugation after iron-loading for $1.5 \mathrm{wk}$, $3 \mathrm{wk}, 5 \mathrm{wk}$, and $1 \mathrm{yr}$; distribution patterns for a control rat are given for comparison. Fractions (N, M, L, P, S) are represented on the ordinate by the relative specific activity of the constituent (percentage of total activity/percentage of total protein) and cumulatively on the abscissa by its percentage protein. $\beta$-gal, $\beta$-galactosidase (a lysosome enzyme); APDI, alkaline phosphodiesterase I (a plasma membrane enzyme); MDH, malate dehydrogenase (a largely mitochondrial enzyme). Esterase, when measured using O-nitrophenyl acetate, is a microsomal enzyme; LDH, lactate dehydrogenase (a cytosolic enzyme). Recovery of enzymes was calculated by summing the activities in the five fractions for a given enzyme and dividing this number by the total activity for the same enzyme in the homogenate; for these experiments, recovery averaged between 92.6 and $105.7 \%$ for all enzymes for all groups studied.

hepatic iron concentration and lysosomal latency was found (Fig. 4).

Hepatic activity and biliary outputs of lysosomal enzymes

Activities in liver of the three lysosomal enzymes were significantly $(P=0.02)$ different in iron-loaded rats compared with controls (Table III). Biliary outputs of all three lysosomal enzymes were significantly less in iron-loaded rats compared with controls (Table III). Also, the activities of lysosomal enzymes excreted into bile in $24 \mathrm{~h}$, expressed as a percentage of the total hepatic content of lysosomal enzymes, was significantly less in iron-loaded rats compared with controls (Table III). In in vitro experiments, no effect was noted on lysosomal enzyme activities in liver and bile with the addition of ferric chloride at concentrations up to $2.0 \mathrm{mg} / \mathrm{ml}$.

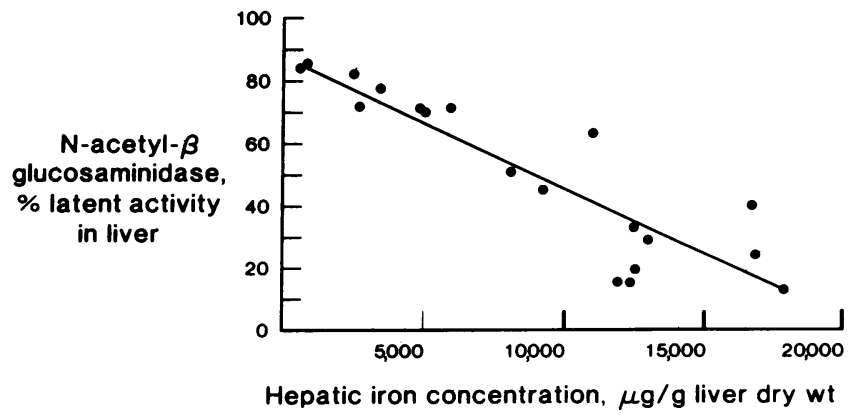

Figure 4. Relationship between hepatic iron concentration and latent activity of $N$-acetyl- $\beta$-glucosaminidase in rat liver. Latency was determined as described in Methods. There was a significant inverse relationship $(r=0.90, P<0.001)$ between hepatic iron concentration and lysosomal latency. 
Table III. Hepatic Content and Biliary

Output of Lysosomal Enzymes*

\begin{tabular}{|c|c|c|c|}
\hline & Controls & Iron-loaded & $P$ value \\
\hline & $n=10$ & $n=9$ & \\
\hline \multicolumn{4}{|l|}{$\begin{array}{l}\text { Lysosomal enzyme activity in } \\
\text { liver }(U / g \text { liver })\end{array}$} \\
\hline$N$-acetyl- $\beta$-glucosaminidase & $\begin{array}{r}1.15 \\
( \pm 0.13)\end{array}$ & $\begin{array}{r}1.61 \\
( \pm 0.13)\end{array}$ & $<0.02$ \\
\hline$\beta$-galactosidase & $\begin{array}{r}0.40 \\
( \pm 0.04)\end{array}$ & $\begin{array}{r}0.43 \\
( \pm 0.05)\end{array}$ & $<0.02$ \\
\hline$\beta$-glucuronidase & $\begin{array}{r}1.31 \\
( \pm 0.10)\end{array}$ & $\begin{array}{r}0.97 \\
( \pm 0.10)\end{array}$ & $<0.02$ \\
\hline \multicolumn{4}{|l|}{$\begin{array}{l}\text { Lysosomal enzyme outputs } \\
\text { into bile ( } m U / 24 h \text { per } g \\
\text { liver) }\end{array}$} \\
\hline$N$-acetyl- $\beta$-glucosaminidase & $\begin{array}{r}66.2 \\
( \pm 13.4)\end{array}$ & $\begin{array}{c}26.7 \\
( \pm 4.6)\end{array}$ & $<0.0005$ \\
\hline$\beta$-glucuronidase & $\begin{array}{r}53.2 \\
( \pm 17.9)\end{array}$ & $\begin{array}{c}10.1 \\
( \pm 1.3)\end{array}$ & $<0.0005$ \\
\hline$\beta$-galactosidase & $\begin{array}{r}15.4 \\
( \pm 2.3)\end{array}$ & $\begin{array}{r}8.9 \\
( \pm 1.0)\end{array}$ & $<0.0005$ \\
\hline \multicolumn{4}{|l|}{$\begin{array}{l}\text { Lysosomal enzyme output } \\
\text { into bile (24-h output as } \\
\text { a percentage of total } \\
\text { liver content) }\end{array}$} \\
\hline$N$-acetyl- $\beta$-glucosaminidase & $\begin{array}{r}5.2 \\
( \pm 1.7)\end{array}$ & $\begin{array}{c}1.1 \\
( \pm 0.3)\end{array}$ & $<0.008$ \\
\hline$\beta$-glucuronidase & $\begin{array}{r}4.0 \\
( \pm 1.3)\end{array}$ & $\begin{array}{r}0.83 \\
( \pm 0.3)\end{array}$ & $<0.006$ \\
\hline$\beta$-galactosidase & $\begin{array}{c}4.1 \\
( \pm 1.5)\end{array}$ & $\begin{array}{r}1.2 \\
( \pm 0.3\end{array}$ & $<0.05$ \\
\hline
\end{tabular}

* Results are presented as mean $\pm \mathrm{SEM}$.

\section{Relationship between biliary iron output and release of lysosomal enzymes into bile}

The relationship between the outputs into bile of iron and $\beta$ galactosidase in control and iron-loaded rats is shown by regression analysis in Fig. 5. In iron-loaded rats, there was a significant

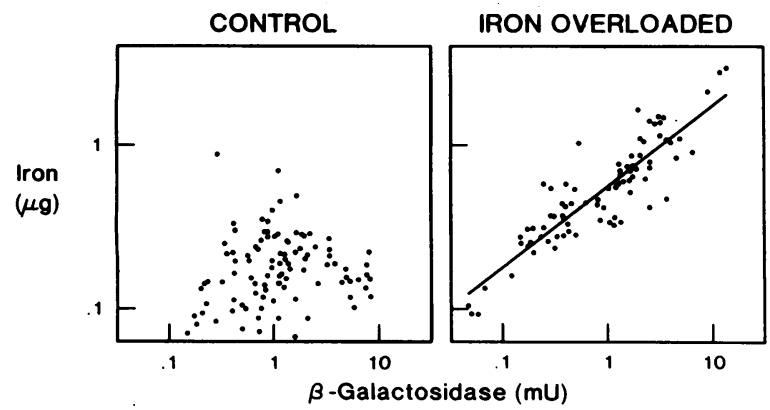

Figure 5. Relationship of outputs into bile of $\beta$-galactosidase and iron in control $(n=10)$ and iron-loaded $(n=9)$ rats. Each point represents the amount of iron and $\beta$-galactosidase in a 2-h bile sample collected for $24 \mathrm{~h}$ from rats with complete bile fistulae. The correlation coefficient for iron output vs. the output of $\beta$-galactosidase was 0.88 in ironloaded rats $(P<0.001)$ and -0.43 in control rats $(P>0.05)$.

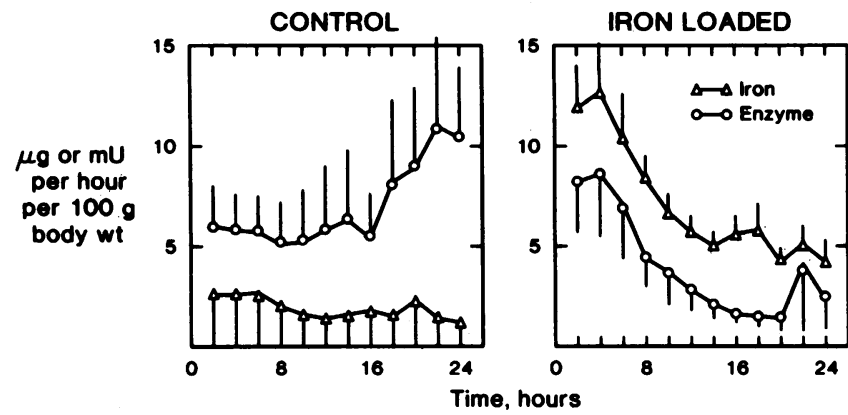

Figure 6. Excretory patterns of iron and a lysosomal enzyme, $N$-acetyl- $\beta$-glucosaminidase, into bile in control $(n=10)$ and iron-loaded $(n$ $=9$ ) rats. Mean \pm SEM.

correlation between the two-hourly outputs of iron and $\beta$-galactosidase $(r=0.88, P<0.001)$. Similar significant correlations between two-hourly outputs of iron and $N$-acetyl- $\beta$-glucosaminidase $(r=0.85, P<0.001)$ and $\beta$-glucuronidase $(r=0.83, P$ $<0.001$ ) were found. In contrast, in control rats, these relationships were poor and not significant: $N$-acetyl- $\beta$-glucosaminidase $(r=-0.417), \beta$-glucuronidase $(r=-0.497)$, or $\beta$-galactosidase $(r=-0.432)$. In all rats studied, no significant relationships were found between the biliary excretion patterns of iron and alkaline phosphodiesterase I or total protein. A comparison of the 24-h excretory patterns for iron and a lysosomal enzyme in control and iron-loaded rats is shown in Fig. 6. A similarity in excretory patterns for iron and $N$-acetyl- $\beta$-glucosaminidase is seen in the iron-loaded rats over $24 \mathrm{~h}$.

\section{Effect of colchicine on biliary excretion of lysosomal enzymes and iron}

The outputs of the three lysosomal enzymes and iron were measured in bile after the injection of colchicine or normal saline in normal and iron-loaded rats (Fig. 7). We had previously shown that colchicine, but not saline or lumicolchicine, markedly altered the release of lysosomal enzymes into bile. (6) The biliary output of $\beta$-galactosidase but not iron was altered in normal rats after the administration of colchicine (Fig. 7); these changes in

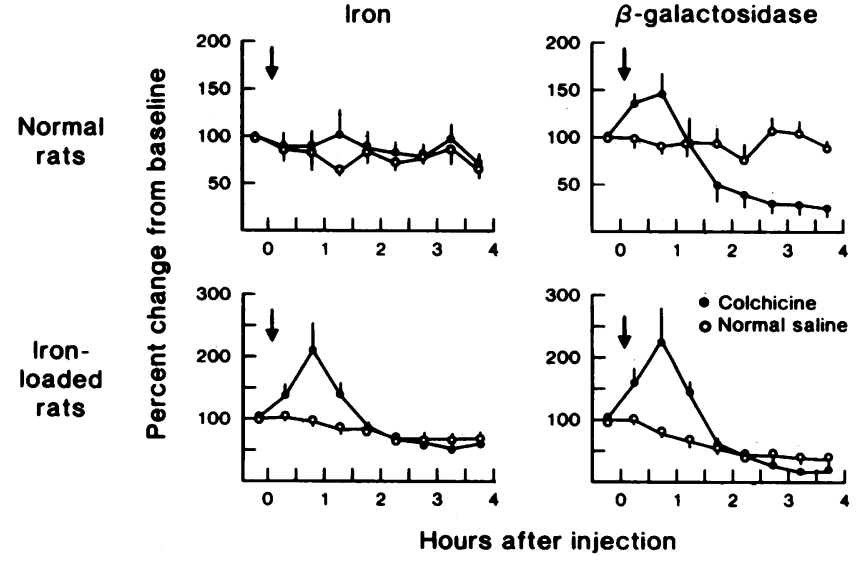

Figure 7. Biliary output of $\beta$-galactosidase and iron in normal ( $n$ $=11)$ or iron-loaded $(n=11)$ rats after the administration of saline or colchicine ( $50 \mu \mathrm{mol} / \mathrm{kg}$ body $\mathrm{wt})$. The lysosomal enzyme and iron output for each half hour after treatment are plotted as a percentage of the output in the half hour before treatment. Data are mean $\pm S E$; arrows indicate time saline or colchicine was administered. 
biliary lysosomal enzyme output after colchicine were similar to those previously reported by us (6). In contrast, $1 \mathrm{~h}$ after the administration of colchicine to iron-loaded rats, there was a parallel increase in the biliary outputs of both iron and $\beta$-galactosidase compared with those given saline. There was a similar, parallel increase in the biliary outputs of iron and $N$-acetyl- $\beta$ glucosaminidase $(221 \%$ increase) and $\beta$-glucuronidase $(254 \%$ increase) after the administration of colchicine to iron-loaded rats (data not shown).

\section{Discussion}

The major findings of this study relate to subcellular aspects of biliary iron excretion. Our results show that, in the rat, experimental iron-overload causes a dramatic increase in hepatic iron content, a sequestration of excess iron in increased numbers of hepatocyte lysosomes, and an increase in biliary iron excretion that is closely coupled to the biliary outputs of three lysosomal enzymes under both basal and stimulated (i.e., colchicine treatment) conditions. We interpret these data to indicate that biliary iron excretion from hepatocyte lysosomes is a major excretory route for excess hepatic iron.

Effect of iron-loading on hepatic and biliary iron. Iron-loading by oral carbonyl iron in the rat has advantages over other ironoverload models. We as well as Bacon et al. (16) have found this method to be efficient, since only 3 mo of oral iron-loading results in hepatic iron concentrations comparable to those found in genetic hemochromatosis. In addition, the cellular distribution of iron within the liver is predominantly in hepatocytes, a situation that is also similar to genetic hemochromatosis. In other experimental iron-overload models, the iron is distributed mostly within the nonparenchymal cells of the liver. Finally, as in early genetic hemochromatosis, iron deposition after iron-loading with carbonyl iron occurs predominately in periportal hepatocytes. Before this study, the subcelluar distribution of iron in the liver of this model had not been reported (see below).

Inclusion of $2 \%$ carbonyl iron in the diet for 3 mo resulted in a 45-fold increase in hepatic iron compared with controls. This marked increase in hepatic iron concentration was associated with a twofold increase in biliary iron output. These observations have at least two implications: first, release of iron into bile may serve as an excretory pathway by which the liver can dispose of excess amounts of hepatic iron in conditions of hepatic iron-overload; and second, this excretory pathway for excess hepatic iron is limited, since a 45 -fold increase in hepatic iron concentration was accompanied by only a twofold increase in biliary iron excretion. This latter situation contrasts with that seen in hepatic copper-overload in which there seems to be a greater ability of the liver to respond to states of excess hepatic copper by accelerating the rate of biliary copper excretion in proportion to the degree of hepatic copper-overload (29).

Subcellular distribution of hepatic iron. Several lines of evidence from this study using independent biochemical and morphologic techniques establish that the excess hepatic iron that accumulates after oral carbonyl iron is progressively sequestered in hepatocyte lysosomes. First, hepatocyte lysosomes in ironloaded rats were dramatically altered in their morphologic appearance; after 3 mo of iron-loading, pericanalicular lysosomes were enlarged and contained electron-dense, hexagonal material characteristic of ferritin. Second, using quantitative morphometric techniques, we observed a progressive increase in the number of pericanalicular lysosomes that paralleled the pro- gressive increase in total hepatic iron. Third, $x$-ray microanalysis showed that these lysosome-like structures in the pericanalicular areas contained iron and that the ratio of lysosomal to nonlysosomal iron increased as the total hepatic iron content rose. Hultcrantz et al. (28) have shown that the iron-containing organelles in iron overload liver are lysosomes using histochemical staining for acid phosphatase. Finally, there was a close, inverse correlation between the total hepatic iron content and the integrity of lysosomal membranes, as assessed biochemically by the latency of lysosomal $N$-acetyl- $\beta$-glucosaminidase.

These morphologic and biochemical data indicate that the excess iron that accumulated in the hepatocytes after addition of $2 \%$ carbonyl iron to the diet of rats is largely if not entirely sequestered in hepatocyte lysosomes. In addition, the results show that the excess lysosomal iron markedly and progressively increases the fragility of lysosomes by an as yet unclear mechanism. Since lysosomal sequestration of excess hepatic iron and ironinduced, increased fragility of hepatocyte lysosomes are also hallmarks of genetic hemochromatosis (30), it seems that the carbonyl-iron, over-loaded rat can serve as an important animal model for the study of this poorly understood disease.

It might seem that the results from our cell fractionation studies do not support the conclusion that excess iron is sequestered in hepatic lysosomes. By this technique, most of the iron seemed to be present in the nonparticulate or cytosolic fraction of the cell in the iron-loaded rats. However, the apparent localization of iron to the cytosolic fraction in the iron-loaded rats is almost certainly the result of disruption during homogenization of lysosomes made extremely fragile by excess intralysosomal iron. This interpretation is based on two observations, one biochemical and one morphologic. First, the progressive decrease in the relative specific activity of the lysosomal marker enzyme, $\beta$-galactosidase, that occurred with sequential ironloading shows that there was leakage of this enzyme into the cytosolic fraction after disruption of lysosomes during homogenization. Moreover, the degree of leakage was proportional to the increase in the iron-induced fragility of lysosomes, as assessed by latency measurements. Recent data from in vitro studies employing lysosomes purified from rat liver suggest that the release of iron from lysosomes results from iron-induced peroxidative damage of lysosomal membranes (31). Second, the results from the combined electron microscopic, $x$-ray microanalysis data show clearly that, in vivo, the excess iron remains sequestered in lysosomes. This situation may differ from that seen in genetic hemochromatosis, in which Peters (30) has postulated a leakage in vivo of excess iron from lysosomes into the cytosol. Thus, we conclude that the apparent cytosolic localization of excess iron by differential centrifugation reflects release of iron in vitro from fragile lysosomes during the homogenization process. These observations point out the importance of employing marker enzymes and performing latency determinations when one uses tissue fractionation to study the subcellular distribution of cellular constituents of interest. They also highlight the advantage of using two independent techniques (i.e., tissue fractionation and x-ray microanalysis) to assess the subcellular localization of specific elements such as iron.

Origin of biliary iron. Our previous observations of coordinate biliary excretion of lysosomal hydrolases under a variety of experimental conditions $(2,4-7)$ suggest that there is bulk exocytic discharge of lysosomal contents into the biliary canaliculus. The demonstration of coupling between biliary iron excretion and release of lysosomal enzymes into bile in the iron- 
loaded rat suggests that the excess iron that accumulates in hepatocyte lysosomes after iron-loading is also released from lysosomes into bile by exocytosis. We have previously shown high concentrations of alkaline phosphodiesterase I in bile (2) and have proposed that this enzyme originates from the canalicular membrane. The coupling of biliary iron with lysosomal enzyme but not alkaline phosphodiesterase I suggests the biliary excretion of iron involves discharge of lysosomes into bile but not solubilization of canalicular membrane proteins.

The observation that iron-loading was associated with an increase in biliary iron excretion that occurred concomitantly with a decrease in biliary lysosomal enzyme release is difficult to interpret with confidence given our conclusion that biliary iron originates from hepatocyte lysosomes by bulk release. It certainly remains possible that we are underestimating the amount of lysosomal enzyme activity in the bile of iron-loaded rats, although this seems unlikely based on our in vitro mixing experiments. Reduced biliary output of lysosomal enzymes in iron-loaded rats could be due to a reduction in enzyme content per lysosome in conjugation with no alteration in the number of lysosomes releasing their contents into bile. We are not aware of a method to measure enzyme content per lysosome; therefore, this hypothesis cannot be readily tested. Another interpretation that we favor is that sequestration of excess iron in hepatocyte lysosomes somehow suppresses the fusion of lysosomes with the canalicular membrane. This interpretation would be compatible with the simultaneous increase in biliary excretion of iron seen in conjunction with the decrease in biliary excretion of lysosomal enzymes since fewer lysosomes containing larger amounts of iron would be available to fuse with the canalicular membrane to release their contents into bile. In addition, such an explanation would also conform to two other experimental results; first, that the number of lysosomes in the pericanalicular area increased after iron-loading, which suggests an accumulation of iron-loaded lysosomes around the canaliculus; and second, as discussed earlier, that the ability of the liver to accelerate its biliary excretion of excess iron sequestered in hepatocyte lysosomes is apparently limited. Whether such an apparent ironinduced suppression of lysosomal enzyme release into bile reflects iron-induced alterations in the lipid or protein composition of lysosomal membranes or damage to nonlysosomal cellular constituents involved in vesicle movement (e.g., microtubules) will need to be assessed in future studies.

We did not find a close relationship between biliary iron excretion and the release of lysosomal enzymes into bile in control rats under either basal or drug-stimulated conditions. These results suggest that in states of normal hepatic iron stores, biliary iron may be derived from a hepatocyte pool other than lysosomes. The source of biliary iron in control animals may be the cytosol since: $(a)$ our tissue fractionation studies showed hepatic iron to be primarily localized to the cytosolic fraction in control rats whose lysosomal membranes were not fragile and in whom, therefore, such a localization is a valid description of the subcellular location of iron in vivo; and $(b)$ our $\mathrm{x}$-ray microanalysis studies did not demonstrate localization of iron in lysosomes in control rats.

Colchicine, a microtubule binding agent, has been shown in a variety of cells to alter extracellular release of excretory products (32-34) by affecting the intracellular movement of vesicles. It seems likely that microtubules play a role in biliary iron excretion since we found that colchicine administration markedly altered biliary iron output in iron-loaded rats. Colchicine-enhanced re- lease of iron into bile was associated with a concurrent augmentation in the excretion of lysosomal enzymes into bile, a finding that further supports our hypothesis that biliary iron is derived from hepatocyte lysosomes.

Higher biliary output of iron and of lysosomal enzymes in iron-loaded rats after the administration of colchicine may reflect an increased number of pericanalicular lysosomes in the condition of iron-overload associated with a colchicine-induced increased rate of fusion of hepatocyte lysosomes with biliary canaliculi. We have previously suggested the occurrence of such a "washout" effect based on our observations in normal rats of an increased release of lysosomal contents into bile, which was associated with a diminution in the number of pericanalicular lysosomes after the administration of colchicine (6). Additional morphologic studies are needed to examine quantitatively the effect of microtubule binding agents on the number of pericanalicular lysosomes and their interaction with canalicular membrane in this iron-overloaded model.

Bradford et al. (15) noted the accumulation of iron-laden lysosomes in the pericanalicular region of the hepatocyte and detected ferritin and hemosiderin in bile under conditions of excess hepatic iron. The finding that biliary iron is in the form of ferritin, in addition to the previous observation that ferritin accumulates in lysosomes in states of hepatic iron overload, further supports the hypothesis that biliary iron is derived from hepatocyte lysosomes. Bradford et al. concluded that biliary iron was derived from hepatocyte lysosomes even though they found no relationship between biliary excretion of acid phosphatase, a lysosomal enzyme, and the release of iron into bile. In contrast to our study, however, Bradford and co-workers did not make serial measurements of biliary iron and lysosomal enzyme outputs over time and did not directly demonstrate the intracellular site of excess iron accumulation.

Pathophysiologic and therapeutic implications. Our data suggest that iron moves across the hepatocyte to the canaliculus by a vesicular transport process involving lysosomes. It has been proposed that the limited capacity of the cytocavitary network to excrete iron storage proteins is fundamental to the pathogenesis of cellular iron-overload (35). Indeed, congenital or acquired iron-overloaded diseases of the liver might involve primary or secondary defects in lysosomal function. Supporting this concept is our observation of a significantly lower biliary lysosomal enzyme excretion in iron-loaded rats compared with controls, a finding which, as briefly discussed above, suggests excess iron may induce a defect in the lysosome-to-bile excretory pathway. Further experiments will be needed to define the role of altered vesicular transport in the pathogenesis of hepatic iron-overload.

Drugs that alter vesicular transport, such as colchicine, may have potential therapeutic benefit in patients with iron-overload diseases. The fate of biliary iron in the intestinal tract would determine the effectiveness of such a treatment. Biliary iron may have a similar fate to biliary copper, which is poorly absorbed by the intestine after biliary excretion (36). We are currently investigating the fate of biliary iron in the intestine and the effect of long-term colchicine administration on hepatic iron concentrations and biliary iron excretion in iron-loaded rats.

\section{Acknowledgments}

We would like to thank Marilyn Breyer for typing the manuscript, and Dr. Sidney Phillips, Dr. Gregory Gores, and Dr. Laurence Miller for reviewing the manuscript. We are also indebted to Dr. John T. McCall for iron measurements of liver and bile samples. 
This work was supported by National Institutes of Health grants AM 24031 and RR585B, by an American Liver Foundation fellowship to Dr. LeSage, and by the Mayo Clinic and Foundation.

\section{References}

1. de Duve, D. 1963. The lysosome concept. In Lysosomes, a CIBA Foundation Symposium. A. V. A. deReuck and M. P. Cameron, editors. Little, Brown, and Co., Boston. 1-35.

2. LaRusso, N. F., and S. Fowler. 1979. Coordinate secretion of acid hydrolases in rat bile. Hepatocyte exocytosis of lysosomal protein. $J$. Clin. Invest. 64:948-954.

3. de Duve, C., and R. Wattiaux. 1966. Functions of lysosomes. Annu. Rev. Physiol. 28:435-492.

4. Lopez del Pino, V., and N. F. LaRusso. 1981. Dissociation of bile flow and biliary lipid secretion from biliary lysosomal enzyme output in experimental cholestasis. J. Lipid Res. 22:229-235.

5. LaRusso, N. F., L. J. Kost, J. A. Carter, and S. S. Barham. 1982. Triton WR 1339, a lysosomotropic compound, is excreted into bile and alters the biliary excretion of lysosomal enzymes and lipids. Hepatology (Baltimore). 2:209-215.

6. Sewell, R. B., S. S. Barham, and N. F. LaRusso. 1983. Effect of chloroquine on the form and function of hepatocyte lysosomes: morphologic modifications and physiologic alterations related to the biliary excretion of lipids and proteins. Gastroenterology. 85:1146-1153.

7. Sewell, R. B., S. S. Barham, A. R. Zinsmeister, and N. F. LaRusso. 1984. Microtubule modulation of biliary excretion of endogenous and exogenous hepatic lysosomal constituents. Am. J. Physiol. 9:G8-G15.

8. LaRusso, N. F. 1984. Proteins in bile: how do they get there and what do they do. Am. J. Physiol. 247:6199-6205.

9. Sewell, R. B., S. J. Mao, T. Kawamoto, and N. F. LaRusso. 1983. Apoproteins of high, low and very low density lipoproteins in human bile. J. Lipid Res. 24:391-401.

10. Grace, N. D., and L. W. Powell. 1974. Iron storage disorders of the liver. Gastroenterology. 64:1257-1283.

11. Barry, M. L., D. M. Flynn, E. A. Letsky, and R. A. Risdon. 1974. Long-term chelation therapy in thalassaemia major: effect of iron concentration, liver histology, and clinical progress. Br. Med. J. 2:16-20.

12. Bothwell, T. H., R. W. Charlton, and H. C. Seftel. 1965. Oral iron overload. S. Afr. Med. J. 39:892-900.

13. Arbrogh, B. A. M., H. Glaumann, and J. L. E. Ericsson. 1974. Studies on iron loading of rat liver lysosomes: effects on the liver and distribution and fate of iron. Lab. Invest. 30:664-673.

14. Bessis, M., and J. Caroli. 1959. A comparative study of hemochromatosis by electron microscopy. Gastroenterology. 37:538-549.

15. Bradford, W. D., J. G. Elchlepp, A. U. Arstila, B. R. Trump, and T. D. Kinney. 1969. Iron metabolism and cell membranes: relation between ferritin and hemosiderin in bile and biliary excretion of lysosomal contents. Am. J. Pathol. 56:201-228.

16. Bacon, B. R., A. S. Tavill, G. M. Brittenham, C. H. Park, and R. O. Recknagel. 1983. Hepatic lipid peroxidation in vivo in rats with chronic iron overload. J. Clin. Invest. 71:429-439.

17. de Duve, C., B. C. Pressman, and R. Gianetto. 1955. Tissue fractionation studies. 6. Intracellular distribution patterns of enzymes in rat liver tissue. Biochem. J. 60:604-617.

18. Peters, T. J., M. Miller, and C. de Duve. 1972. Lysosomes of the arterial wall. I. Isolation and subcellular fractionation of cells from normal rabbit aorta. J. Exp. Med. 136:1117-1139.

19. Beaufay, H., A. A. Costesec, E. Feytmans, D. Thines-Sempoux, M. Robbi, and J. Berthet. 1974. Analytical study of microsomes and isolated subcellular membranes from rat liver. J. Cell Biol. 61:188-200.

20. Dupourque, D., and F. Kern. 1969. Cytoplasmic and mitochondrial malate dehydrogenase from beef kidney. Methods Enzymol. 13: 116-122.

21. Leighton, F., D. Poole, H. Beaufy, P. Daudhuin, J. W. Coffey, S. Fowler, and C. de Duve. 1968. The large scale separation of perioxisomes, mitochondria and lysosomes from the livers of rats injected with Triton WR-1339. J. Cell Biol. 37:482.

22. Reeves, W. J., and G. M. Fimognari. 1966. Lactic dehydrogenase: Heart (H4). Methods Enzymol. 9:288-294.

23. Lowry, O. H., N. F. Rosenbrough, and A. L. Farr. 1951. Protein measurement with the Folin phenol reagent. J. Biol. Chem. 193:265275.

24. LeSage, G. D., W. P. Baldus, U. F. Fairbanks, A. H. Baggenstoss, J. T. McCall, B. S. Moore, H. F. Taswell, and H. Gordon. 1983. Hemochromatosis: genetic or alcoholic-induced. Gastroenterology. 84:14711477.

25. McDowell, E. M., and B. F. Trump. 1976. Histologic fixatives suitable for diagnostic light and electron microscopy. Arch. Pathol. Lab. Med. 100:405-414.

26. Scheuer, P. J. 1973. Liver biopsy interpretation. William and Wilkins, editors. Baltimore, MD. 121-127.

27. Spurr, A. R. 1969. A low viscosity epoxy embedding medium for electron microscopy. J. Ultrastruct. Res. 26:31-42.

28. Hultcrantz, R., B. Arborgh, R. Wroblewski, and J. L. E. Ericsson. 1979. Studies on the rat liver following iron overload: Electron probe x-ray microanalysis of acid phosphatase and iron. Am. J. Pathol. 96: 625-639.

29. Gross, J. B., L. Kost, P. Tietz, S. S. Barham, J. McCall, and N. F. LaRusso. 1984. Gastroenterology. 86:1322. (Abstr.)

30. Peters, T. J., C. Selden, and C. A. Seymour. 1976. Lysosomal disruption in the pathogenesis of hepatic distribution in the pathogenesis of hepatic damage in primary and secondary haemochromatosis. In Iron metabolism. CIBA Foundation Symposium. Elsevier/North Holland, Amsterdam. No. 51. 317-329.

31. Mak, I. T., and W. B. Weglicki. 1985. Characterization of ironmedicated peroxidative injury in isolated hepatocyte lysosomes. J. Clin. Invest. 75:58-63.

32. Hoffstein, S., I. M. Goldstein, and G. Weissman. 1977. Role of microtubule assembly in lysosomal enzyme secretion from human polymorphonuclear leukocytes. J. Cell Biol. 73:242-256.

33. Stephens, R. E., and K. T. Edds. 1976. Microtubules: structure, chemistry, and function. Physiol. Rev. 56:709-777.

34. Redman, C. M., D. Banerjee, K. Howell, and G. E. Palade. 1976. Colchicine inhibition of plasma protein release from rat hepatocyte. $J$. Cell Biol. 66:42-59.

35. Trump, B. E., J. M. Valigorsky, A. U. Arstila, W. J. Mergner, and T. D. Kinney. 1973. The relationship of intracellular pathways of iron metabolism to cellular iron overload and the iron storage diseases. Am. J. Pathol. 72:295-323.

36. Frommen, D. 1971. The binding of copper by bile and serum. Clin. Sci. 41:485-493. 